\title{
Detection of CD10, CD34 and their combined expression on Childhood Acute Lymphoblastic Leukemia and the association with clinical outcome in Indonesia
}

\author{
Eddy Supriyadi ${ }^{1 \star}$, Anjo JP Veerman ${ }^{1,2}$, Sutaryo ${ }^{1}$, Ignatius Purwanto ${ }^{1}$, Peter M. vdVen ${ }^{4}$, Jacqueline Cloos $^{2,3}$ \\ Correspondence: e.supriyadi@gadjahmada.edu \\ ${ }^{1}$ Pediatric Hematology Oncology Division, Department of Pediatrics, Dr Sardjito Hospital -Faculty of Medicine Universitas Gadjah \\ Mada, Yogyakarta, Indonesia. \\ ${ }^{2}$ Pediatric Oncology/Hematology Division, Department of Pediatrics, VU University Medical Center, Amsterdam, the Netherlands. \\ ${ }^{3}$ Department of Hematology, VU University Medical Center, Amsterdam, the Netherlands; \\ ${ }^{4}$ Department of Epidemiology and Biostatistics, VU University Medical Center, Amsterdam, the Netherlands.
}

\begin{abstract}
Background: Immunophenotyping has been implemented in the diagnosis of children with acute leukemia in Yogyakarta, Indonesia. The aim of this study was to determine whether expression of CD10 and/or CD34 could be used as additional prognostic markers for children with acute lymphoblastic leukemia (ALL) treated on the Indonesia ALL 2006 protocol.

Materials \& Methods: Of 211 ALL patients immunophenotype was determined and related to clinical data. Patient outcome was calculated as overall survival and event free survival, in which events were defined as: induction failure, death or relapse.

Results: In the overall patients cohort, combination of CD10 and/or CD34 expression is an independent favorable prognostic factor in both univariate and multivariate analyses.

In B-lineage ALL expression of CD10, CD34 and CD10+ and/or CD $34^{+}$were: $78 \%, 59 \%$ and $90 \%$ respectively. Although CD10, CD34 and the combined expression were associated with favorable outcome in the overall cohort, none of these parameters remained a significant independent risk factor after multivariate analysis in B-lineage leukemia.

In T-lineage leukemia, expressions of CD10, CD34 and CD10 ${ }^{+}$and/or CD34+ were: $30 \%, 21 \%$ and $49 \%$ respectively. Co-expression of CD10 and/or CD34 in this subgroup was a significant favorable prognostic factor in both univariate and multivariate analysis.

Conclusion: In our Indonesian population CD10 expression alone and in combination with CD34 expression are prognostically significant positive parameters.

Keywords: immunophenoyping, childhood leukemia, Acute Lymphoblastic Leukemia, CD10, CD34, clinical outcome, Indonesia, developing country, Yogyakarta
\end{abstract}

\section{Introduction}

Immunophenotyping of abnormal hematological cells is very useful for the diagnosis, classification, cost-effective treatment and prognostic evaluation in patients with hematological malignancies. [1-5] CD10 and CD34 are surface markers that have been reported to have prognostic relevance in childhood acute lymphoblastic leukemia (ALL), but the results were conflicting [6-10].

CD10 was originally known as common ALL antigen (CALLA). It was one of the first markers to identify acute leukemia in children. In the hematopoietic system, CD10 regulates stromal dependent B lymphopoiesis. The majority of B-lineage ALL cases expressed CD10. However, expression of CD10 has also been reported in other types of leukemia $[11,12]$. In B-lineage $A L L$, the percentage of cells expressing CD10 decreases in more mature forms $[\mathbf{1}, \mathbf{2}]$. Positive CD10 expression was associated with favorable clinical outcome [13]. In addition, lower white blood cell count (WBC), younger age, and subtype FAB L1 were associated with higher expression of CD10 [14]. Results of CD10 expression vary among different studies, ranging from $68 \%$ to $96 \%$ in B-lineage ALL, and 18\% - 45\% in T-lineage ALL (Table 1). CD34 is a human stage-specific hematopoietic differentiation antigen, and expressed in early-undifferentiated hematopoietic stem cells, both in lymphoid and myeloid pathways. In leukemic

(c) 2012 Supriyadi et al; licensee Herbert Publications Ltd. This is an open access article distributed under the terms of Creative Commons Attribution License (http://creativecommons.org/licenses/by/3.0), This permits unrestricted use, distribution, and reproduction in any medium, provided the original work is properly cited. 
Table 1. Literature overview on percentage of CD10 and CD34 positive cells in various studies.

\begin{tabular}{lccccc}
\hline \multirow{2}{*}{ Study } & \multicolumn{3}{c}{ B-lineage ALL } & \multicolumn{3}{c}{ T-lineage ALL } & Reference \\
\cline { 2 - 5 } & CD10 & CD34 & CD10 & CD34 & \\
\hline Pui, 1993 & 94 & 83 & 40 & 46 & {$[7,13]$} \\
Stella, 1995 & - & 70 & - & - & {$[19]$} \\
Larson, 1995 & - & - & - & 50 & {$[37]$} \\
Vanhaeke, 1995 & - & 60 & - & 40 & {$[18]$} \\
Luna, 1997 & 68 & - & 29 & - & {$[23]$} \\
Cascavilla, 1997 & - & 86 & - & - & {$[17]$} \\
Consolini, 1998 & 96 & - & 18 & - & {$[6]$} \\
Campana, 2000 & 95 & - & 45 & - & {$[2]$} \\
Basso, 2001 & - & 70 & - & 10 & {$[22]$} \\
Bachir, 2009 & 91 & 74 & 21 & 42 & {$[38]$} \\
Dakka, 2009 & 80 & 48 & 21 & 16 & {$[10]$} \\
\hline This study & $\mathbf{7 6}$ & $\mathbf{5 3}$ & $\mathbf{2 7}$ & $\mathbf{2 4}$ & - \\
\hline
\end{tabular}

cells, it remains expressed over several stages of lymphoid and myeloid maturation $[15,16]$. The clinical significance of CD34 expression has been debated. It appears that the prognostic value depends on the type of leukemia and protocol used [7,17-19].

Studies on the combination of CD10 and CD34 expression in correlation with clinical outcome are limited. Dakka, et al. 2009, found that in B-lineage $\mathrm{ALL}$, a combination of $\mathrm{CD} 10^{+} \mathrm{CD} 34^{+} \mathrm{CO}-$ expression was found in $44 \%$ of cases, while CD10+CD34 was found in $34 \%$. In T-lineage ALL, CD10-CD34 was found in the majority (76\%) and was associated with worse prognosis with a 5 years survival rate of $22 \%$ [10]. To elucidate the relevance of the combined CD10 and CD34 expression as independent prognostic factor in children with ALL in Yogyakarta we related the expression of CD10, CD34 and the combination of both markers to clinical characteristics as well as to outcome.

\section{Material and Methods \\ Patients}

From March 2006 to July 2010, 239 consecutive children with newly diagnosed with ALL were admitted to the Dr. Sardjito Hospital, Yogyakarta, Indonesia. Inclusion criteria for this study are: 0-14 years of age, no prior treatment, treated with Indonesia 2006 ALL protocol. Exclusion criteria are: prior treatment and mature-B ALL. Indonesia Protocol 2006 has a 4-drug treatment in induction phase: Corticosteroid (Prednisone/ Dexamethasone), Vincristine, L-Asparaginase and Anthracyclin. In induction phase this protocol uses 4 doses of daunorubicin $\left(30 \mathrm{mg} / \mathrm{m}^{2}\right)$ for SR and HR patients. In case of daunorubicin was not available it was replaced with doxorubicin in a dose of $20 \mathrm{mg} / \mathrm{m}^{2}$. After induction patients received a consolidation and maintenance treatment. In HR patients, a re-induction course was inserted after the consolidation treatment. Otherwise, the SR and HR protocol consisted of the same drugs, doses and schedules.

From January 2006 we started to randomize prednisone and dexamethasone in standard risk only. Since May 2009 high-risk patients were also randomized. Patients in the dexamethasone arm received prednisone $60 \mathrm{mg} / \mathrm{m}^{2} /$ day during one week pre-phase, then dexamethasone $4 \mathrm{mg} /$ $\mathrm{m}^{2} /$ day during induction and in blocks during maintenance for SR patients or dexamethasone $6 \mathrm{mg} / \mathrm{m}^{2} /$ day during one week pre-phase, as well as in induction, re-induction and maintenance treatment blocks for HR patients. Patients in the prednisone arm received prednisone $60 \mathrm{mg} / \mathrm{m}^{2} /$ day during pre-phase, then $40 \mathrm{mg} / \mathrm{m}^{2} /$ day during induction and maintenance treatment blocks (SR patients) or prednisone $40 \mathrm{mg} / \mathrm{m}^{2} /$ day during pre-phase, induction, re-induction and in maintenance treatment blocks (HR patients).Patients who are not treated with this protocol were excluded from survival analysis.

Among these children, 211 cases met these inclusion criteria and complete data were available for both clinical data and immunophenotyping, including evaluation of CD10 and CD34 expression.

\section{Morphology Diagnosis}

Bone Marrow (BM) and Peripheral Blood smears were stained using May Grunwald-Giemsa Method, Periodic Acid-Schiff, Sudan Black and myeloperoxidase. Morphology diagnosis was based on FAB criteria.

\section{Immunophenotyping}

BM cells were also tested on 3 colors BD FACS-Calibur for immunophenotyping. The panel of monoclonal antibodies was: CD2, cytoplasmic CD3 (cCD3), CD7 for T-lineage ALL, CD10, CD19, CD22, cytoplasmic CD79a (cCD79a) for B-lineage ALL, CD13, CD33, cytoplasmic MPO (cMPO) and CD117 for myeloid lineage and CD45, lgG1, IgM, Tdt, and CD34 for non

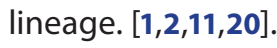

For membrane staining monoclonal antibodies were added (lgG1, CD2, CD7, CD10, CD13, CD19, CD22, CD33, CD34, CD117 and $C D 45$ ) to $30 \mu \mathrm{l}$ of cell suspension in separate polystyrene tubes. This suspension was then incubated in the dark for 15 minutes at room temperature. After incubation, $16.6 \mu$ lpara formaldehyde (4\%) was added to the cell suspensions and incubated for 4 minutes at room temperature, in the dark. Then $1 \mathrm{ml}$ lysing solution was added and lysed 10 minutes at room temperature, in the dark. Cells were then centrifuged $1500 \mathrm{rpm}$ for 5 minutes, cell pellets was washed twice, and re-suspended in 300-500 $\mu \mathrm{l} \mathrm{PBS.} \mathrm{For} \mathrm{Cytoplasmic} \mathrm{staining}$ (clgG1, cCD79a, cCD3, cMPO and cTdT) cell suspensions were incubated for 15 minutes at room temperature then washed twice and re-suspended 300-500 $\mu \mathrm{l}$ of PBS. Run in the BD FACS-Calibur. 
Table 2. Univariate cox-regression analysis of event free survival and overall survival in the total ALL patient group

\begin{tabular}{|c|c|c|c|c|c|c|c|}
\hline & \multicolumn{3}{|c|}{ EFS } & \multirow[b]{2}{*}{$p$ value } & \multicolumn{3}{|c|}{ OS } \\
\hline & $\mathrm{n}(\%)$ & HR & $(95 \% \mathrm{Cl})$ & & HR & $95 \% \mathrm{Cl}$ & p value \\
\hline \multicolumn{8}{|l|}{$\underline{\text { Sex }}$} \\
\hline Female & $86(41)$ & 1 & & & 1 & & \\
\hline Male & $125(59)$ & 1.5 & $0.92-2.38$ & 0.11 & 0.65 & $0.41-1.04$ & 0.07 \\
\hline \multicolumn{8}{|l|}{ Age at diagnosis } \\
\hline $1-9$ years & 165(78) & 1 & & & 1 & & \\
\hline$<1$ and $>10$ years & $46(22)$ & 1.9 & $1.14-3.30$ & 0.01 & 1.67 & $0.99-2.84$ & 0.06 \\
\hline \multicolumn{8}{|l|}{ WBC at diagnosis } \\
\hline$<50.000 / \mathrm{mm} 3$ & $169(80)$ & 1 & & & 1 & & \\
\hline$>50.000 / \mathrm{mm} 3$ & $42(20)$ & 1.5 & $0.82-2.66$ & 0.19 & 1.47 & $0.83-2.61$ & 0.18 \\
\hline \multicolumn{8}{|l|}{ Classification* } \\
\hline Standard Risk & $94(45)$ & 1 & & & 1 & & \\
\hline High Risk & $117(55)$ & 2.2 & $1.22-4.02$ & 0.01 & 1.86 & $1.06-3.26$ & 0.03 \\
\hline \multicolumn{8}{|l|}{$\underline{F A B}$} \\
\hline ALL-L1 & $175(83)$ & 1 & & & 1 & & \\
\hline ALL-L2 & $36(17)$ & 1.2 & $0.64-2.09$ & 0.63 & 0.82 & $0.43-1.57$ & 0.55 \\
\hline \multicolumn{8}{|l|}{ Immunophenotyping } \\
\hline B-lineage ALL & $178(84)$ & 1 & & & 1 & & \\
\hline T-lineage ALL & $33(16)$ & 1.4 & $0.75-2.50$ & 0.31 & 1.45 & $0.82-2.56$ & 0.20 \\
\hline \multicolumn{8}{|l|}{ CD10 expression } \\
\hline CD10+ & $148(70)$ & 1 & & & 1 & & \\
\hline CD10- & $63(30)$ & 1.9 & $1.19-3.15$ & 0.01 & 2.13 & $1.33-3.41$ & 0.002 \\
\hline \multicolumn{8}{|l|}{ CD34 expression } \\
\hline CD34+ & $112(53)$ & 1 & & & 1 & & \\
\hline CD34- & $99(47)$ & 1.1 & $0.72-1.89$ & 0.52 & 1.25 & $0.78-2.00$ & 0.36 \\
\hline \multicolumn{8}{|c|}{ Combination CD10 and CD34 } \\
\hline CD10+CD34+ & $84(40)$ & 1 & & & 1 & & \\
\hline CD10+CD34- & $64(30)$ & 0.9 & $0.47-1.67$ & 0.71 & 0.91 & $0.48-1.72$ & 0.78 \\
\hline CD10-CD34+ & $28(13)$ & 1.4 & $0.66-2.95$ & 0.39 & 1.43 & $0.67-3.03$ & 0.36 \\
\hline CD10-CD34- & $35(17)$ & 2.2 & $1.18-4.15$ & 0.01 & 2.81 & $1.56-5.07$ & 0.001 \\
\hline \multicolumn{8}{|l|}{ CD10- and CD34- } \\
\hline CD10+ and/or CD34+ & $176(83)$ & 1 & & & 1 & & \\
\hline CD10-CD34- & $35(17)$ & 2.2 & $1.27-3.75$ & 0.01 & 2.73 & $1.65-4.53$ & $<0.001$ \\
\hline
\end{tabular}

${ }^{\star}$ Risk Classification based on NCI criteria; HR: Hazard Ratio was calculated with correction for protocol used

\section{Statistical analysis}

The variables tested included, age, WBC, French-AmericanBritish (FAB) subtype, risk classification, CD10, CD34 expression and Indonesia 2006 protocol with either prednisone or dexamethasone. For CD10 expression, a 10\% threshold was selected to identify positive cases while for CD34 a $20 \%$ threshold was determined to be the optimal cut-off point. The settings were based on literature and the frequency distribution of our data. We selected the values of CD10 and CD34 that maximized the hazard ratio as the optimal the cutoff values. These cut-off levels are similar to those in most of the mentioned studies.

The difference in frequencies between the $\mathrm{CD}_{10} 0^{+}$and CD10 or CD34 ${ }^{+}$and CD34 groups were examined using Chisquare test. Most patients were treated with dexamethasone $(161 / 211)$ whereas a prednisone protocol was used for the other patients. All hazard ratios calculated where corrected for the protocol (dexamethasone/prednisone) used.

Event-free survival (EFS) was calculated from date of start treatment to date of first event: induction failure, death, or relapse. Overall survival (OS) was calculated from date of start treatment to date of death of any cause. Complete remission (CR) was determined at the end of induction treatment and defined as no detectable lymphoblast on peripheral blood or cerebrospinal fluid and less than $5 \%$ lymphoblasts in active haemopoiesis marrow and no physical signs of infiltrative leukemic cells anywhere. Induction failure defined as no complete remission. OS and EFS analysis was done using Kaplan-Meier method and compared using the Log rank test. Hazard ratios were estimated and multivariate models were fitted using Cox regression. A p-value less than 0.05 was used as level for statistical significance. All Variables with $p<0.20$ in univariate analyses were included in multivariate analyses. All analyses were done in SPSS version 15. 


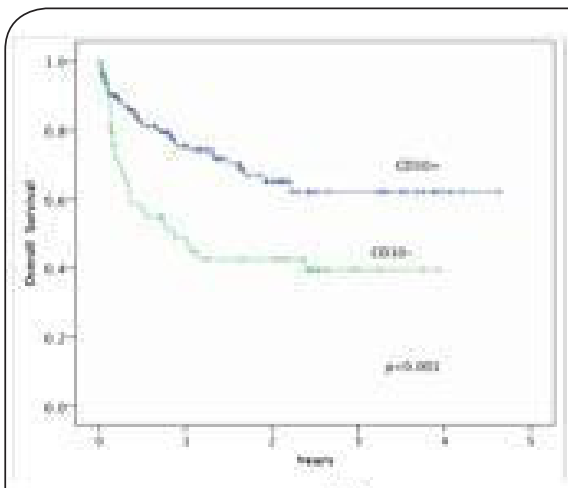

(A)

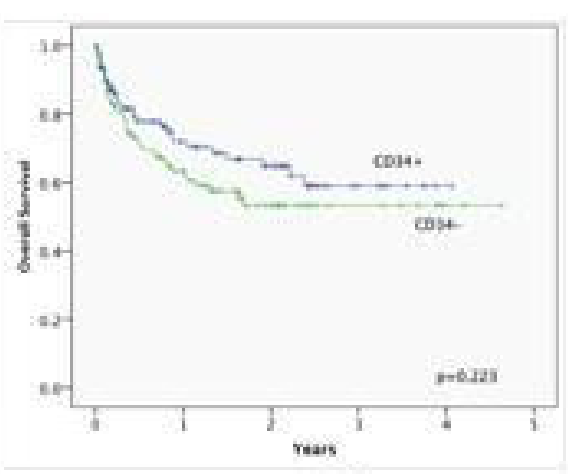

(B)

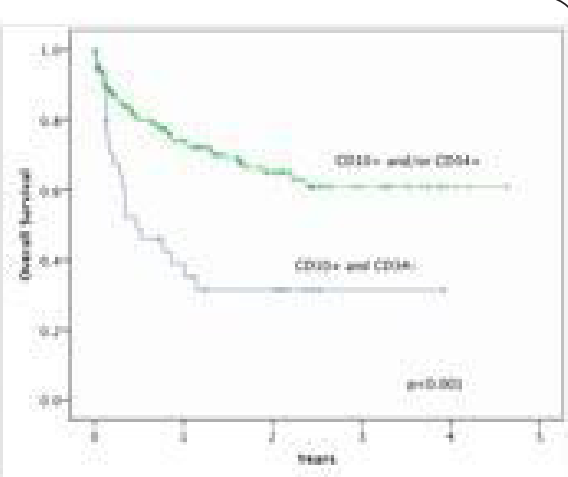

(C)

Figure 1. Overall survival of all children treated on the Indonesia 2006 ALL protocol. (A) Stratified by CD10 expression (CD10 positive $>10 \%$; log-rank: $p<0.001$ ). (B) Stratified by CD34 expression (CD34 positive $>20 \%$; log-rank: $p=0.223$ ). (C) Stratified by expression of CD10 and/or CD34 (log-rank, p<0.001).

\section{Results}

From 239 patients, 28 patients were excluded (12 patients used Wijaya Kusuma-2000 protocol, 5 had treatment before, 4 refused to treat, 3 patients were non conclusive, 3 got suboptimal treatment, 1 patient aged more than 15 years). Two hundred and eleven patients were analyzed for clinical and biological features and their characteristics are summarized in Table 2. Death was the event was most frequently observed $(n=50,23.7 \%)^{\prime}$. This because abandonment is no longer considered to be an event. Fourteen patients (6.6\%) relapsed and 4 patients (1.9\%) failed in induction. In the whole patients cohort, EFS at 4 years was $58 \% \pm 4 \%$ while OS at 4 years was $84 \% \pm 4 \%$.

In the whole patient cohort, CD10 antigen was expressed in 148 (70\%) of 211 patients tested. Relative frequency of positive CD10 expression was significantly higher $(p<0.001)$ in SR stratification (83\% of 94 patients) than in HR stratification (60\% of 117 patients).

CD34 expression was found in 112 (53\%) of 211 patients tested. This expression was also significantly associated with risk stratification $(p<0.001)$; relative frequency of positive CD34 expression was found higher in SR group (67\%) than in HR group (42\%).

In addition to the effect of single CD10 expression, there was a significant $(p<0.001)$ association between the combined CD10 and CD34 expression and risk stratification. Relative frequency of positive CD10 and positive CD34 co-expression was $56 \%$ of $\mathrm{CD}_{10}{ }^{+} \mathrm{CD} 34^{+}$in the SR group compared to $27 \%$ of $\mathrm{CD} 10^{+} \mathrm{CD}_{34}{ }^{+}$in the HR group. CD10 ${ }^{-}$and CD34- occurred in $6.4 \%$ of patients in SR group and $24.8 \%$ of patients in the HR group.

In univariate analysis for EFS in the whole cohort, age at diagnosis, risk classification, expression of CD10 and the combination of CD10 and CD34 were found to be statistically significant (Table 2). We also analyzed clinical associations with expression of $\mathrm{CD}_{10}{ }^{+}$and/or $\mathrm{CD} 34^{+}$and thereby compared $\mathrm{CD} 10^{-}$ $\mathrm{CD}^{-} 4^{-}$versus all other groups $\left(\mathrm{CD} 10^{+} \mathrm{CD} 34^{+}, \mathrm{CD} 10^{+} \mathrm{CD} 34^{-}\right.$and $\mathrm{CD}^{-} \mathrm{CD}^{-} 4^{+}$) since calculations including the four categories showed that only the double negatives significantly differed from the reference category of double positives.

Multivariate analysis for EFS showed only age category and CD10-CD34 to be statistically significant. After correction for the protocol used hazard ratios were 2.11 (95\% Cl: $1.26-$ $3.54, p=0.004)$ for age category and $2.36(95 \% \mathrm{Cl}: 1.39-4.02$, $\mathrm{p}=0.002$ ) for CD10-CD34.

In univariate analysis for OS in the whole cohort, risk classification, expression of CD10 and the combination of CD10-CD34 were found to be statistically significant (Table 2). Multivariate analysis for OS showed that only age category and CD10-CD34- remained statistically significant. Hazard ratios were 1.87 (95\% Cl: $1.11-3.13, \mathrm{p}=0.02)$ for age category and 2.7 (95\% Cl: $1.65-4.54, \mathrm{p}<0.001)$ for CD10CD34- when corrected for protocol we use.

EFS for $\mathrm{CD}_{10}{ }^{+}$patients was $63 \% \pm 6 \%$ and for $\mathrm{CD}^{3} 4^{-}$was $44 \% \pm 7 \%, p=0.004$. For CD34+ EFS at 4 years was $60 \% \pm 6 \%$ and EFS for CD34- was $55 \% \pm 6 \%, p=0.403$.

Kaplan-Meier analyses for OS showed that expression of CD10 and the combined expression $\mathrm{CD}_{10}{ }^{+}$and/or $\mathrm{CD} 34^{+}$had $\mathrm{a}$ better prognosis (log-rank test $p<0.001$ ) while CD34+ alone did not reach significance (Figure 1). Patients with $\mathrm{CD} 10^{+}$had an OS at 4 years of $62 \% \pm 6 \%$, vs. CD10 of $40 \% \pm 7 \%$. for CD34 $4^{+}$ alone this was $59 \% \pm 6 \%$ vs. CD34- $53 \% \pm 6 \%$. OS at 4 years for the combined expression $\mathrm{CD}_{10}{ }^{+}$and/or CD34 ${ }^{+}$was $61 \% \pm$ $5 \%$ vs. $31 \% \pm 9 \%$ for CD 10 CD34 
Supriyadi et al. Journal of Cancer Therapeutics \& Research 2012,

http://www.hoajonline.com/journals/pdf/2049-7962-1-20.pdf

Table 3. Clinical characteristics of B- and T-lineage ALL according to CD10 expression

\begin{tabular}{|c|c|c|c|c|c|c|c|c|}
\hline \multirow[t]{2}{*}{ Variable } & \multicolumn{4}{|c|}{ B-lineage ALL, n=178 } & \multicolumn{4}{|c|}{ T-lineage ALL, $n=33$} \\
\hline & & $\begin{array}{c}\text { CD10 } \\
\text { n (\%) }\end{array}$ & $\begin{array}{l}\text { CD10 } \\
\text { n (\%) }\end{array}$ & $p$ value & $n(\%)$ & $\begin{array}{l}\text { CD10 } \\
\text { n (\%) }\end{array}$ & $\begin{array}{l}\text { CD10 } \\
\text { n (\%) }\end{array}$ & $p$ value \\
\hline \multicolumn{9}{|l|}{ Sex } \\
\hline Male & $100(56)$ & $80(80)$ & $20(20)$ & 0.37 & $25(76)$ & $6(24)$ & $19(76)$ & 0.16 \\
\hline Female & $78(44)$ & $58(74)$ & $20(26)$ & & $8(24)$ & $4(50)$ & $4(50)$ & \\
\hline \multicolumn{9}{|l|}{ Age } \\
\hline $1-9$ years & $139(78)$ & $107(77)$ & $32(23)$ & 0.74 & $26(79)$ & 10(39) & $16(61)$ & 0.05 \\
\hline$<1 \&>10$ years & $39(22)$ & $31(80)$ & $8(20)$ & & $7(21)$ & $0(0)$ & $7(100)$ & \\
\hline \multicolumn{9}{|l|}{ WBC } \\
\hline$<50.000 / \mathrm{mm}^{3}$ & $148(83)$ & $115(78)$ & $33(22)$ & 0.90 & $21(64)$ & $8(38)$ & $13(62)$ & 0.20 \\
\hline$>50.000 / \mathrm{mm}^{3}$ & $30(17)$ & $23(77)$ & $7(23)$ & & $12(36)$ & $2(17)$ & $10(83)$ & \\
\hline \multicolumn{9}{|l|}{ FAB } \\
\hline L1 & $145(82)$ & $115(79)$ & $30(21)$ & 0.23 & $30(91)$ & $8(27)$ & $22(72)$ & 0.15 \\
\hline L2 & $33(18)$ & $23(70)$ & $10(30)$ & & $3(9)$ & $2(67)$ & $1(33)$ & \\
\hline \multicolumn{9}{|l|}{ Risk* } \\
\hline SR & $94(53)$ & $78(83)$ & $16(17)$ & 0.07 & 0 & $0(0)$ & $0(0)$ & - \\
\hline $\mathrm{HR}$ & $84(47)$ & $60(71)$ & $24(29)$ & & 33 & $10(30)$ & $23(70)$ & \\
\hline
\end{tabular}

${ }^{*}$ Risk Classification based on NCI criteria

Table 4. Clinical characteristics of B- and T-lineage ALL according to CD34 expression

\begin{tabular}{|c|c|c|c|c|c|c|c|c|}
\hline & & \multicolumn{3}{|c|}{ B-lineage ALL, $n=178$} & \multicolumn{4}{|c|}{ T-lineage ALL, $n=33$} \\
\hline & & $\begin{array}{l}\text { CD34 }^{+} \\
\text {n (\%) }\end{array}$ & $\begin{array}{l}\text { CD34 } \\
\text { n (\%) }\end{array}$ & $\begin{array}{c}p \\
\text { value }\end{array}$ & & $\begin{array}{l}\text { CD34 }^{+} \\
\text {n (\%) }\end{array}$ & $\begin{array}{l}\text { CD34 } \\
\text { n (\%) }\end{array}$ & $p$ value \\
\hline \multicolumn{9}{|l|}{ Sex } \\
\hline Male & $100(56)$ & $55(55)$ & $45(45)$ & 0.22 & $25(76)$ & $7(28)$ & $18(72)$ & 0.09 \\
\hline Female & $78(44)$ & $50(64)$ & $28(36)$ & & $8(24)$ & $0(0)$ & $8(100)$ & \\
\hline \multicolumn{9}{|l|}{ Age } \\
\hline $1-9$ years & $139(78)$ & $86(62)$ & $53(38)$ & 0.14 & $26(79)$ & 5 (19) & $21(81)$ & 0.59 \\
\hline$<1 \&>10$ years & $39(22)$ & $19(49)$ & $20(51)$ & & $7(21)$ & $2(29)$ & $5(71)$ & \\
\hline \multicolumn{9}{|l|}{ WBC } \\
\hline$<50.000 / \mathrm{mm}^{3}$ & $148(83)$ & $88(60)$ & $60(40)$ & 0.78 & $21(64)$ & $5(24)$ & $16(76)$ & 0.63 \\
\hline$>50.000 / \mathrm{mm}^{3}$ & $30(17)$ & $17(57)$ & $13(43)$ & & $12(36)$ & $2(17)$ & $10(83)$ & \\
\hline \multicolumn{9}{|l|}{ FAB } \\
\hline ALL-L1 & $145(82)$ & $84(58)$ & $61(42)$ & 0.55 & $30(91)$ & $6(20)$ & $24(80)$ & 0.59 \\
\hline ALL-L2 & $33(18)$ & $21(64)$ & $12(36)$ & & $3(9)$ & $1(33)$ & $2(67)$ & \\
\hline \multicolumn{9}{|l|}{ Risk* } \\
\hline$S R$ & $94(53)$ & $63(67)$ & $31(33)$ & 0.02 & 0 & $0(0)$ & $0(0)$ & - \\
\hline $\mathrm{HR}$ & $84(47)$ & $42(50)$ & $42(50)$ & & $33(100)$ & $7(21)$ & $26(79)$ & \\
\hline
\end{tabular}

\section{B-lineage}

For further analysis the patient group was stratified by lineage. In the B-lineage ALL group, the majority of samples were $\mathrm{CD} 10^{+}, 78 \%$ of 178 patients. Clinical and biological features of B-lineage patients and their characteristics are summarized in Table 3.
Clinical characteristics of B- and T-lineage ALL according to CD34 expression were shown in Table 4. CD10+ and/or CD34 ${ }^{+}$was found in 160/178 (90\%). Expression of CD10 and/ or CD34 was associated with risk classification, $p=0.037$. The minority (36\%) of CD10+CD34+ patients was high risk, whereas the majority (67\%) of CD10-CD34 patients was classified as high risk. 
Table 5. Univariate cox-regression analysis of event free survival in the B- and T-lineage ALL patient group

\begin{tabular}{|c|c|c|c|c|c|c|c|c|}
\hline \multirow{2}{*}{ Variables } & \multicolumn{4}{|c|}{ B-lineage ALL, $n=178$} & \multicolumn{4}{|c|}{ T-lineage ALL, $n=32$} \\
\hline & $\mathbf{n}$ & HR & $(95 \% \mathrm{Cl})$ & $\mathbf{p}$ & $\mathbf{n}$ & HR & $(95 \% \mathrm{Cl})$ & $\mathbf{p}$ \\
\hline \multicolumn{9}{|l|}{$\underline{\text { Sex }}$} \\
\hline Female & 78 & 1 & & & 8 & 1 & & \\
\hline Male & 100 & 1.79 & $1.05-3.06$ & 0.03 & 24 & 0.76 & $0.23-2.99$ & 0.76 \\
\hline \multicolumn{9}{|c|}{ Age at diagnosis (vears) } \\
\hline $1-9$ years & 139 & 1 & & & 25 & 1 & & \\
\hline$<1$ and $>10$ years & 39 & 1.70 & $0.93-3.11$ & 0.09 & 7 & 3.76 & $1.22-11.6$ & 0.02 \\
\hline \multicolumn{9}{|l|}{$\underline{W B C}$ at diagnosis } \\
\hline$<50.000 / \mathrm{mm}^{3}$ & 148 & 1 & & & 21 & 1 & & \\
\hline$>50.000 / \mathrm{mm}^{3}$ & 30 & 1.18 & $0.57-2.47$ & 0.65 & 11 & 1.90 & $0.60-5.95$ & 0.27 \\
\hline \multicolumn{9}{|l|}{ Classification* } \\
\hline Standard Risk & 94 & 1 & & & & & & \\
\hline High Risk & 84 & 2.12 & $1.14-3.97$ & 0.02 & 32 & & & \\
\hline \multicolumn{9}{|l|}{$\underline{F A B}$} \\
\hline ALL-L1 & 145 & 1 & & & 29 & 1 & & \\
\hline ALL-L2 & 33 & 1.10 & $0.58-2.10$ & 0.77 & 3 & 2.46 & $0.54-11.2$ & 0.24 \\
\hline \multicolumn{9}{|l|}{ CD10 expression } \\
\hline $\mathrm{CD}_{10}+$ & 138 & 1 & & & 10 & 1 & & \\
\hline $\mathrm{CD}_{10}$ & 40 & 1.60 & $0.90-2.85$ & 0.11 & 22 & 3.73 & $0.82-17.0$ & 0.09 \\
\hline \multicolumn{9}{|l|}{ CD34 expression } \\
\hline $\mathrm{CD}_{3} 4^{+}$ & 105 & 1 & & & 7 & 1 & & \\
\hline CD34- & 73 & 1.16 & $0.68-1.99$ & 0.59 & 25 & 0.75 & $0.21-2.73$ & 0.66 \\
\hline
\end{tabular}

Combination CD10 and CD34

\begin{tabular}{|c|c|c|c|c|c|c|c|c|}
\hline $\mathrm{CD} 10^{+} \mathrm{CD} 34^{+}$ & 83 & 1 & & & 1 & \multicolumn{3}{|c|}{ Numbers are too small to analyze } \\
\hline $\mathrm{CD} 10^{+} \mathrm{CD} 34^{-}$ & 55 & 1.07 & $0.56-2.05$ & 0.85 & 9 & & & \\
\hline $\mathrm{CD} 10^{-} \mathrm{CD} 34^{+}$ & 22 & 1.42 & $0.63-3.23$ & 0.40 & 6 & & & \\
\hline $\mathrm{CD} 10^{-} \mathrm{CD} 34^{-}$ & 18 & 1.91 & $0.90-4.20$ & 0.11 & 16 & & & \\
\hline \multicolumn{9}{|l|}{ CD10- and CD34- } \\
\hline CD10+ and/or CD34+ & 160 & 1 & & & 16 & 1 & & \\
\hline CD10'CD34- & 18 & 1.77 & $0.86-3.64$ & 0.12 & 16 & 3.2 & $0.96-10.5$ & 0.06 \\
\hline
\end{tabular}

${ }^{\star}$ Risk Classification based on NCI criteria; HR: Hazard Ratio was calculated with correction for protocol used. One patient was excluded from the analysis in the T-lineage group because this patient was treated with SR protocol.

In univariate analyses for EFS using Cox regression was shown in Table 5. Univariate analysis for OS, was presented in Table 6. In a univariate analysis for OS, we found that female patients in B-ALL, have almost twice higher chance to have a worse prognosis (Table 6). The same factors were found to be the only significant predictors for survival in the multivariate analyses in this subgroup.

In Kaplan Meier analysis, patients with CD10 expression had a higher better prognosis, although not statistically significant.
EFS at 4 years was $61 \% \pm 6 \%$ and CD10 was $49 \% \pm 9 \%, p=0.084$. For CD34, Kaplan-Meier analysis showed that patients with CD34 ${ }^{+}$expression had a similar survival compared to patients who were $\mathrm{CD} 34$-Survival of $\mathrm{CD} 10^{+}$and/or $\mathrm{CD} 34^{+}$was $71 \% \pm$ $12 \%$ vs. CD10 CD34 was $29 \% \pm 13 \%$, $p=0.037$. Overall survival curves are shown in Figure 2A, 2B and 2C.

\section{T-lineage}

CD10 expression in T-ALL was $30 \%$ and $\mathrm{CD}^{-} 0^{-}$was a majority 
Table 6. Univariate cox-regression analysis of overall survival in the B- and T-lineage ALL patient group

\begin{tabular}{|c|c|c|c|c|c|c|c|c|}
\hline \multirow{2}{*}{ Variables } & \multicolumn{4}{|c|}{ B-lineage ALL, $n=178$} & \multicolumn{4}{|c|}{ T-lineage ALL, $n=32$} \\
\hline & $\mathbf{n}$ & HR & $(95 \% \mathrm{Cl})$ & $\mathbf{p}$ & $\mathbf{n}$ & HR & $(95 \% \mathrm{Cl})$ & $\mathbf{p}$ \\
\hline \multicolumn{9}{|l|}{$\underline{\text { Sex }}$} \\
\hline Female & 78 & 1 & & & 8 & 1 & & \\
\hline Male & 100 & 0.53 & $0.31-0.91$ & 0.02 & 24 & 1.09 & $0.35-3.42$ & 0.89 \\
\hline \multicolumn{9}{|c|}{ Age at diagnosis (vears) } \\
\hline $1-9$ years & 139 & 1 & & & 25 & 1 & & \\
\hline$<1$ and $>10$ years & 39 & 1.36 & $0.73-2.54$ & 0.33 & 7 & 3.56 & $1.25-10.2$ & 0.02 \\
\hline \multicolumn{9}{|l|}{$\underline{W B C}$ at diagnosis } \\
\hline$<50.000 / \mathrm{mm}^{3}$ & 148 & 1 & & & 21 & 1 & & \\
\hline$>50.000 / \mathrm{mm}^{3}$ & 30 & 1.08 & $0.52-2.24$ & 0.83 & 11 & 2.24 & $0.78-6.42$ & 0.14 \\
\hline \multicolumn{9}{|l|}{ Classification* } \\
\hline Standard Risk & 94 & 1 & & & & & & \\
\hline High Risk & 84 & 1.71 & $0.94-3.08$ & 0.08 & 32 & & & \\
\hline \multicolumn{9}{|l|}{$\underline{F A B}$} \\
\hline ALL-L1 & 145 & 1 & & & 29 & 1 & & \\
\hline ALL-L2 & 33 & 0.86 & $0.43-1.70$ & 0.66 & 3 & 1.01 & $0.13-7.71$ & 0.99 \\
\hline \multicolumn{9}{|l|}{ CD10 expression } \\
\hline $\mathrm{CD} 10^{+}$ & 138 & 1 & & & 10 & 1 & & \\
\hline CD10 & 40 & 1.59 & $0.89-2.83$ & 0.12 & 22 & 9.91 & $1.30-75.8$ & 0.03 \\
\hline \multicolumn{9}{|l|}{ CD34 expression } \\
\hline $\mathrm{CD}_{3} 4^{+}$ & 105 & 1 & & & 7 & 1 & & \\
\hline CD34- & 73 & 1.13 & $0.66-1.93$ & 0.66 & 26 & 1.41 & $0.32-6.27$ & 0.65 \\
\hline \multicolumn{9}{|c|}{ Combination CD10 and CD34 } \\
\hline $\mathrm{CD}_{10} \mathrm{CD}^{+} 4^{+}$ & 83 & 1 & & & 1 & & & \\
\hline $\mathrm{CD} 10^{+} \mathrm{CD} 34^{-}$ & 55 & 1.02 & $0.53-1.94$ & 0.96 & 9 & \multicolumn{3}{|c|}{ Numbers are too small to } \\
\hline $\mathrm{CD}_{10} \mathrm{CD} 4^{+}$ & 22 & 1.37 & $0.61-3.10$ & 0.45 & 6 & & analyze & \\
\hline CD10-CD34 & 18 & 1.88 & $0.86-4.11$ & 0.11 & 16 & & & \\
\hline \multicolumn{9}{|l|}{$\underline{\text { CD10 }}=$ and CD34 } \\
\hline $\mathrm{CD}_{10} 0^{+}$and/or $\mathrm{CD} 34^{+}$ & 160 & 1 & & & 16 & 1 & & \\
\hline CD10-CD34 & 18 & 1.78 & $0.87-3.67$ & 0.12 & 16 & 5.89 & $1.63-21.3$ & 0.007 \\
\hline
\end{tabular}

${ }^{\star}$ Risk Classification based on NCI criteria; HR: Hazard Ratio was calculated with correction for protocol used. One patient was excluded from the analysis in the T-lineage group because this patient was treated with SR protocol.

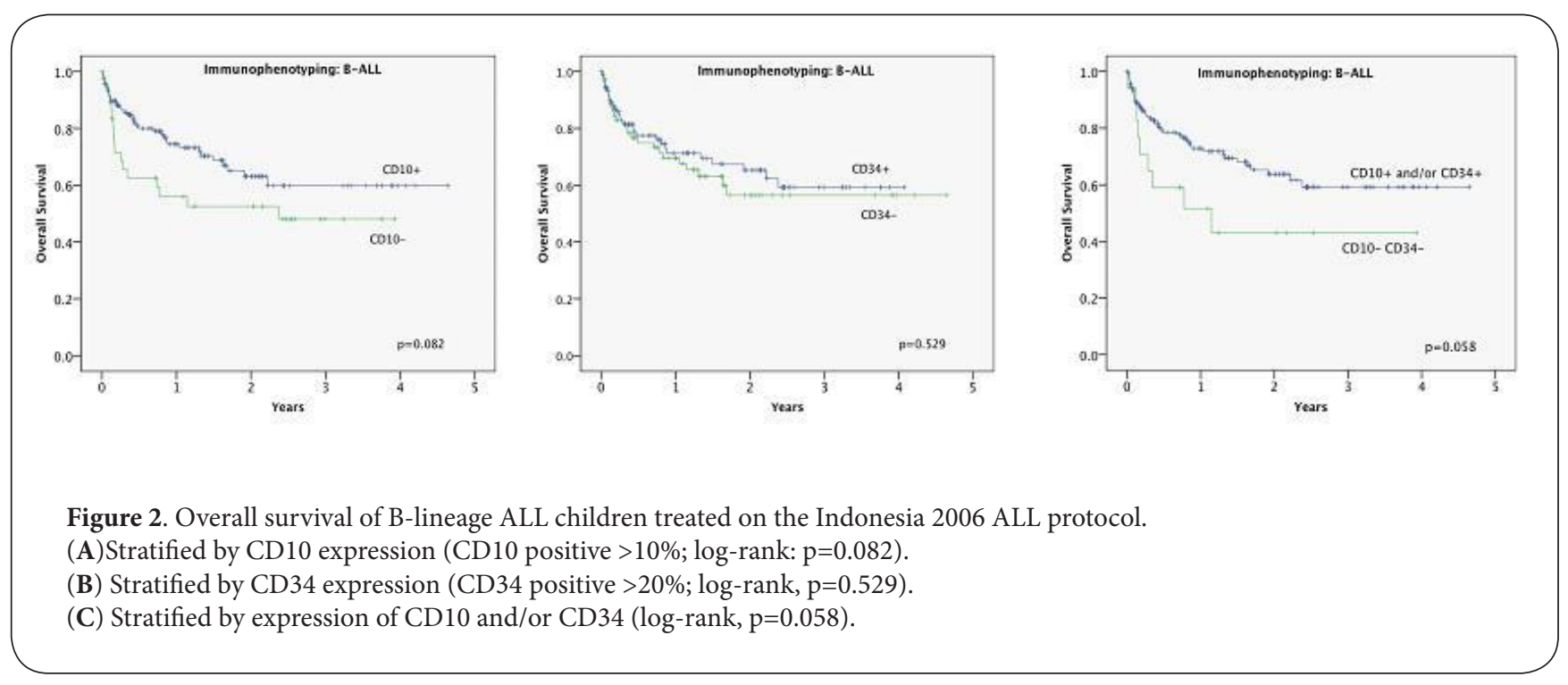



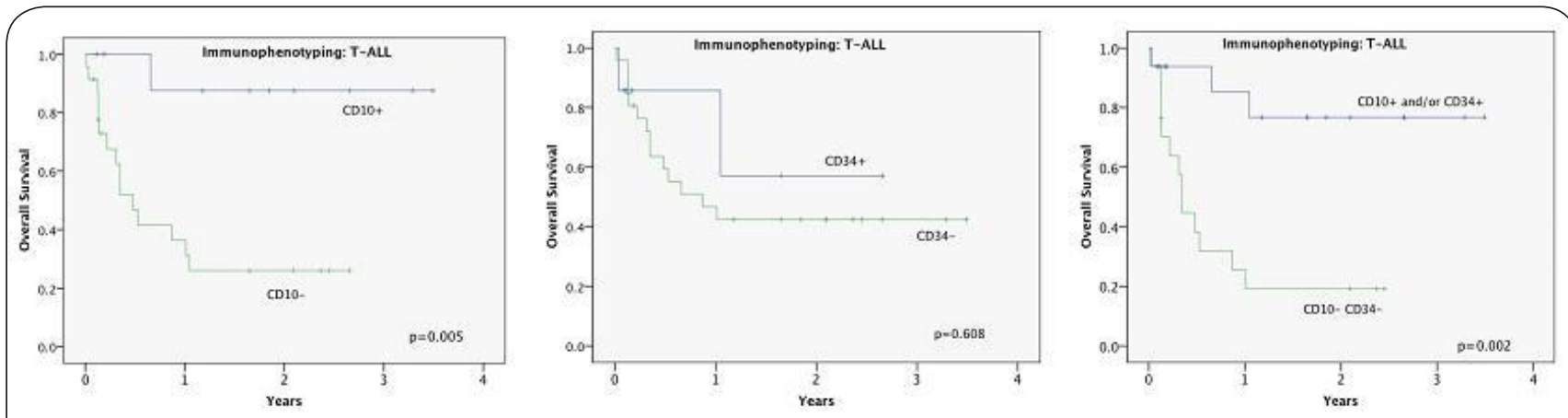

Figure 3. Overall survival of children with T-lineage ALL treated on the Indonesia 2006 ALL protocol.

(A) Stratified by CD10 expression (CD10 positive $>10 \%$; log-rank, $\mathrm{p}=0.005$ ).

(B) Stratified by CD34 expression (CD34 positive $>20 \%$; log-rank, $\mathrm{p}=0.608$ ).

(C) Stratified by expression of CD10 and/or CD34 (log-rank, $\mathrm{p}=0.002$ ).

$70 \%$ of 33 patients. In T-lineage ALL expression of CD10 was found only in age $1-9$ years old $(p=0.049)$. In the T-lineage group analyses of the combination of CD10 and CD34 were restricted to the comparison of $\mathrm{CD} 10^{-} \mathrm{CD} 34^{-}$versus the rest as the sub group $\mathrm{CD} 10^{+} \mathrm{CD} 34^{+}$only contained a single patient and was therefore too small to analyze. The final model only consisted of the independent risk variable WBC and CD10 $\mathrm{CD} 34$. Their hazard ratios corrected for the protocol were 1.65 (95\% Cl: $1.05-2.60$, p-value 0.03$)$ for WBC and $1.98(95 \% \mathrm{Cl}$ : 1.98 - 1.28, p-value 0.002) for CD10-CD34. One patient was excluded from the analysis, because the patient was treated according to the SR protocol.

In univariate analysis for EFS of T-lineage patients were presented in Table 5. In the multivariate analysis for EFS age at diagnosis was the only parameter that remained significant hazard ratio was 3.5 ( $95 \% \mathrm{Cl}: 1.14-10.4, \mathrm{p}=0.04)$.

In univariate analysis for OS, age at diagnosis, CD10 expression and the combination of CD10-CD34- expression were statistically significant (Table 6) In multivariate analysis, only CD10 $\mathrm{CD} 34^{-}$found to be related to OS, with a hazard ratio after corrected to the protocol was 6.1 (95\% Cl: $1.7-$ 21.3, p-value 0.005).Overall survival analysis for CD10, CD34 expression and the combination of $\mathrm{CD}_{10}{ }^{+}$and/or $\mathrm{CD} 34^{+}$are shown in Figure 3A, 3B and $3 \mathrm{C}$.

\section{Discussion}

We examined the expressions of CD10, CD34 and the combination of CD10 and CD34 both in B- and T-lineage ALL. Two hundred and eleven patients were analyzed for the correlation of both markers with the clinical and biological features of those patients. We also analyzed the prognostic significance of both markers in the Indonesian ALL-2006 protocol.
A large percentage of children included abandoned treatment early ( $n=37,17.5 \%)$. Sitaresmi et al. 2009, found that reasons for treatment refusal or abandonment were: financial and transport difficulties, beliefs about curability and side-effects, children's refusal, and dissatisfaction with health-care providers [21].

Studies on the expression of CD10 and CD34, alone or in combination, as a prognostic factor, found discrepancies $[6,7,10,10,22,23]$. These discrepancies may be dependent upon sensitivity of the immunophenotyping, upon patient variables, or upon differences in treatment protocols. In this study, we found $84 \%$ B-lineage ALL and $16 \%$ T-lineage ALL. This result is similar to our previous study [24]. Compared to studies in high income and low-income countries our finding is relatively high for T-lineage ALL [25-35]. Expression of CD10 and CD34 also varies in different studies (Table 1). In these studies of B-lineage ALL, CD10 antigen was detected in $68-96 \%$ and CD34 expression was 48\%-86\%. In T-lineage ALL less patients expressed these markers; CD10 expression was $18-45 \%$ and CD34 was $10 \%-50 \%$. Our result for CD10 and CD34 were in the lower range for both B- and T-lineage ALL as reported by others. The possible reasons for this may be the different cut off points for positivity (range in the literature $5-20 \%)$. Another plausible explanation for the differences in CD10 and CD34 expression can be the different ethnicity and thereby different genetic backgrounds (Asian vs. European/ American) $[22,36]$.

\section{Overall patients}

Studies on the significance of CD10 expression on outcome also showed various results in the literature. Pui et al., [13] and Consolini et al., [6] found that in their patient cohort CD10 expression in B- and T-lineage ALL had no independent 
prognostic significance $[6,13]$. Our results showed that overall; CD10 expression had a significant better survival compared to CD10. CD10 expression had a significant prognostic value in univariate analysis for OS and EFS. But in multivariate analysis for OS and EFS, this expression was no longer significant. The remaining independent prognostic factors were double negativity of CD10 and CD34 besides age at diagnosis and risk classification.

In addition, Pui et al., [7] found that the expression of CD34 was correlated with several favorable features at diagnosis such as age between 1-10 years of age, white race, absence CNS leukemia, low serum LDH, CD10 expression and hyperdiploidy. In concordance with our study, CD34 was associated with standard risk stratification but had no significant impact on prognosis.

A study conducted by Dakka et al., found that the five years survival rate for the $\mathrm{CD}_{10}^{-} \mathrm{CD} 34^{-}$group was only $22 \%$ [10]. In our study, lack of both CD10 and CD34 expression was also related to worse prognosis; OS was $61 \%$ in the combination $\mathrm{CD} 10^{+}$and/or $\mathrm{CD} 34^{+}$group vs. $31 \%$ in the double negative group, $p<0.001$ (Figure 1C).

\section{B-Lineage}

A limited number of studies on CD10 have been done in developing countries. A Study of CD10 in Mexico showed no significant prognostic value, EFS of $\mathrm{CD}_{10} 0^{+}$cases was $78 \%$ and CD10- was 71\% ( $p=0.6)$ [23]. A study in Morocco found that the 5 -year survival rate of $B$-lineage $A L L$ with $C D 10^{+}$is higher than in $\mathrm{CD}^{-}$cases [10]. This result is similar to our findings (Figure 2A).

A study conducted by Cascavilla et al., [17] showed that expression of CD34 antigen was frequently expressed in $B$-lineage ALL and had a positive prognostic factor in childhood ALL. In our study expression of CD34 was associated with SR group. Survival rate between $\mathrm{CD}^{+} 4^{+}$and $\mathrm{CD}_{34}{ }^{-}$patients were similar (Figure 2B).

Studies on co-expression of CD10 and CD34 were limited. A study in Morocco, found in B-lineage ALL, that the co expression was associated with 1-10 years of age at diagnosis, male and low WBC [10]. In our study, co-expression of CD10 and CD34 was associated with SR group. In SR group expression of CD10 and/or CD34 was $94 \%$ while in HR group was $75 \%$ ( $p<0.001)$. The predictive value of the co-expression was less strong in B-ALL group, but that is still may be clinically relevant. However, further research will be needed to establish this.

\section{T-Lineage}

In T-lineage ALL, Han et al., [14] found that CD10 expression was associated with lower WBC. In addition, CD34- was correlated with T-lineage ALL as well as age over 10 years, CNS disease at diagnosis, and higher WBC. In a different study [8], CD34 expression was associated with poor disease free survival and overall survival. A univariate analysis of T-lineage ALL in our study showed that age at diagnosis, CD10 expression and combination of CD10 and CD34 were significantly associated with OS. In multivariate analysis only combination of CD10 and CD34 remained as a significant poor prognostic factor, Hazard Ratio: 5.9, 95\%Cl: 1.6 - 21.3, p=0.007. In Kaplan-Meier analysis patients with CD10 expression in this T-lineage ALL group had a better survival $(p=0.005)$. Although the sample size of our patients was limited, we found that in Kaplan Meier analysis, lack of CD10 and the combination of CD10 and CD34- in T-lineage ALL had a significantly worse prognosis (Figure $3 \mathrm{~A}$ and $\mathbf{3 C}$ ).

Lack of CD10 and CD34 had a negative significant prognostic value especially in both overall and in T-ALL patients, while in B-lineage ALL it was only borderline significant. This fact can be explained because the prevalence of $\mathrm{CD} 10^{-} \mathrm{CD} 34^{-}$was higher in the high-risk group, and all T-ALL cases were high risk (by definition criteria of the protocol).

In T-lineage patients, even though they are HR in particular the $\mathrm{CD} 10^{+}$patients and the combined CD10 and CD34 expression have a relatively good prognosis. Hence, a special care should be taken for those who are in T-lineage group with no expression of CD10 and/or CD34.

\section{Conclusion}

In our Indonesian population of children with ALL we show that it is important to determine the expression of CD10 to better predict the treatment outcome. The expression of CD10 and the combination of CD10 and/or CD34 had a significant better survival.

\section{Acknowledgement}

Dutch Cancer Society Grant (IN-2006) and a DIKTI grant of the Indonesia Ministry of Education support this study. We thank the Estella Fonds for funding some of chemotherapy in this study.

\section{Competing interests}

All authors declare that there is no conflict of interest.

\section{Author contributions}

E.S. acquired patient material, analyzed and interpreted data, drafted the manuscript, I.P. collected clinical data, P.V. advised in statistical analysis of the data and revised the manuscript, S., A.V., J.C. provided the conception and design of the study, analysis and interpretation of data and revised the manuscript. All authors gave final approval of this version to be submitted.

\section{Publication history}

Received:21-May-2012 Revised: 31-July-2012

Accepted: 04-Aug-2012 Published: 10-Aug-2012

\section{References}

1. Behm F, Campana D: Immunophenotyping. In: Acute Leukemias. Edited by Pui CH, 1 edn. Cambridge: Cambridge University Press; 1999: 111135. | Book

2. Campana D, Behm FG: Immunophenotyping of leukemia. Journal of Immunological Methods 2000; 243;(1-2.);59-75. | Article

3. Coustan-Smith E, Sancho J, Hancock ML, Boyett JM, Behm FG, Raimondi $\mathrm{SC}$, et al.: Clinical importance of minimal residual disease in childhood acute lymphoblastic leukemia. Blood 2000; 96;(8.);2691-6. | Article | PubMed

4. Howard SC, Campana D, Coustan-Smith E, Antillon FG, Bonilla M, Fu L, 
et al.: Development of a regional flow cytometry center for diagnosis of childhood leukemia in Central America. Leukemia 2005; 19;(3.);323-5. | Article I PubMed

5. Orfao A, Schmitz G, Brando B, Ruiz-Arguelles A, Basso G, Braylan R, et al.: Clinically useful information provided by the flow cytometric immunophenotyping of hematological malignancies: current status and future directions. Clin Chem 1999; 45;(10.);1708-17. | Article | PubMed

6. Consolini R, Legitimo A, Rondelli R, Guguelmi C, Barisone E, Lippi A, et al.: Clinical relevance of CD10 expression in childhood ALL. The Italian Association for Pediatric Hematology and Oncology (AIEOP). Haematologica 1998; 83;(11.);967-73. | Article | PubMed

7. Pui CH, Hancock ML, Head DR, Rivera GK, Look AT, Sandlund JT, et al.: Clinical significance of CD34 expression in childhood acute lymphoblastic leukemia. Blood 1993; 82;(3.);889-94. | Article I PubMed

8. van Grotel $M$, van den Heuvel-Eibrink MM, van Wering ER, van Noesel MM, Kamps WA, Veerman AJ, et al.: CD34 expression is associated with poor survival in pediatric T-cell acute lymphoblastic leukemia. Pediatr Blood Cancer 2008; 51;(6.);737-40. | Article | PubMed

9. Sidhom I, Shaaban K, Soliman S, Ezzat S, El-Anwar W, Hamdy N, et al.: Clinical significance of immunophenotypic markers in pediatric T-cell acute lymphoblastic leukemia. J Egypt Natl Canc Inst 2008; 20;(2.);11120. | Article | PubMed

10. Dakka N, Bellaoui H, Bouzid N, Khattab M, Bakri Y, Benjouad A: CD10 AND CD34 expression in childhood acute lymphoblastic leukemia in Morocco: clinical relevance and outcome. Pediatr Hematol Oncol 2009; 26;(4.);216-31. | Article | PubMed

11. Bene MC, Bernier M, Castoldi G, Faure GC, Knapp W, Ludwig WD, et al.: Impact of immunophenotyping on management of acute leukemias. Haematologica 1999; 84;(11.);1024-34. | Article | PubMed

12. Shipp MA, Stefano GB, Switzer SN, Griffin JD, Reinherz EL: CD10 (CALLA)/ neutral endopeptidase 24.11 modulates inflammatory peptideinduced changes in neutrophil morphology, migration, and adhesion proteins and is itself regulated by neutrophil activation. Blood 1991; 78;(7.);1834-41. | Article | PubMed

13. Pui CH, Rivera GK, Hancock ML, Raimondi SC, Sandlund JT, Mahmoud $\mathrm{HH}$, et al.: Clinical significance of CD10 expression in childhood acute lymphoblastic leukemia. Leukemia 1993; 7;(1.);35-40. | PubMed

14. Hann IM, Richards SM, Eden OB, Hill FG: Analysis of the immunophenotype of children treated on the Medical Research Council United Kingdom Acute Lymphoblastic Leukaemia Trial XI (MRC UKALLXI). Medical Research Council Childhood Leukaemia Working Party. Leukemia 1998; 12;(8.);1249-55. | PubMed

15. Greaves MF, Brown J, Molgaard HV, Spurr NK, Robertson D, Delia D, et al.: Molecular features of CD34: a hemopoietic progenitor cell-associated molecule. Leukemia 1992; 6 Suppl 1;(31-6. | PubMed

16. Schmitt $C$, Eaves $C J$, Lansdorp PM: Expression of CD34 on human B cell precursors. Clin Exp Immunol 1991; 85;(1.);168-73. | Article | PubMed Abstract | PubMed Full Text

17. Cascavilla N, Musto P, D’Arena G, Ladogana S, Matera R, Carotenuto M: Adult and childhood acute lymphoblastic leukemia: clinico-biological differences based on CD34 antigen expression. Haematologica 1997; 82;(1.);31-7. | Article | PubMed

18. Vanhaeke DR, Bene MC, Garand R, Faure GC: Expression and long-term prognostic value of CD34 in childhood and adult acute lymphoblastic leukemia. Leuk Lymphoma 1995; 20;(1-2.);137-42. | Article | PubMed

19. Stella CC, Cazzola M, De Fabritiis P, De Vincentiis A, Gianni AM, Lanza F, et al.: CD34-positive cells: biology and clinical relevance. Haematologica 1995; 80;(4.);367-87. | Article | PubMed

20. Basso G, Buldini B, De Zen L, Orfao A: New methodologic approaches for immunophenotyping acute leukemias. Haematologica 2001; 86;(7.);675-92. | Article | PubMed

21. Sitaresmi MN, Mostert S, Schook RM, Veerman AJ: Treatment refusal and abandonment in childhood acute lymphoblastic leukemia in Indonesia: an analysis of causes and consequences. Psychooncology 2010; 19;(4.);361-7. | Article | PubMed
22. Basso G, Lanza F, Orfao A, Moretti S, Castoldi G: Clinical and biological significance of CD34 expression in acute leukemia. J Biol Regul Homeost Agents 2001; 15;(1.);68-78. I PubMed

23. Rivera-Luna R, Cardenas-Cardos R, Leal-Leal C, Navarro-Alegria I, Meza-Coria C, Gomez-Martinez $R$, et al.: B-lineage acute lymphoblastic leukemia of childhood. An institutional experience. Arch Med Res 1997; 28;(2.);233-9. I PubMed

24. Supriyadi E, Widjajanto PH, Veerman AJ, Purwanto I, Nency YM, Gunawan S, et al.: Immunophenotypic patterns of childhood acute leukemias in Indonesia. Asian Pac J Cancer Prev 2011; 12;(12.);3381-7. I Article I PubMed

25. Ariffin H, Chen SP, Kwok CS, Quah TC, Lin HP, Yeoh AE: Ethnic differences in the frequency of subtypes of childhood acute lymphoblastic leukemia: results of the Malaysia-Singapore Leukemia Study Group. J Pediatr Hematol Oncol 2007; 29;(1.);27-31. | Article I PubMed

26. Cabrera ME, Labra S, Ugarte S, Matutes E, Greaves MF: [Immunophenotype. Clinical and laboratory features of acute lymphoblastic leukemia in Chile. Study of $\mathbf{5 0 0}$ children and 131 adults]. Rev Med Chil 1996; 124;(3.);293-9. | PubMed

27. Kamps WA, van der Pal-de Bruin KM, Veerman AJ, Fiocco $M$, Bierings $M$, Pieters R: Long-term results of Dutch Childhood Oncology Group studies for children with acute lymphoblastic leukemia from 1984 to 2004. Leukemia 2010; 24;(2.);309-19. | Article | PubMed

28. McNally RJ, Alexander FE, Birch JM: Space-time clustering analyses of childhood acute lymphoblastic leukaemia by immunophenotype. $\mathrm{Br} J$ Cancer 2002; 87;(5.);513-5. | Article | PubMed Abstract | PubMed Full Text

29. Milne E, Royle JA, de Klerk NH, Blair E, Bailey H, Cole C, et al.: Fetal growth and risk of childhood acute lymphoblastic leukemia: results from an Australian case-control study. Am J Epidemiol 2009; 170;(2.);221-8. I Article I PubMed

30. Moricke A, Zimmermann M, Reiter A, Henze G, Schrauder A, Gadner H, et al.: Long-term results of five consecutive trials in childhood acute lymphoblastic leukemia performed by the ALL-BFM study group from 1981 to 2000. Leukemia 2010; 24;(2.);265-84. | Article | PubMed

31. Pui CH, Pei D, Sandlund JT, Ribeiro RC, Rubnitz JE, Raimondi SC, et al.: Long-term results of St Jude Total Therapy Studies 11, 12, 13A, 13B, and 14 for childhood acute lymphoblastic leukemia. Leukemia 2010; 24;(2.);371-82. | Article | PubMed Abstract | PubMed Full Text

32. Rego EM, Garcia AB, Viana SR, Falcao RP: Characterization of acute lymphoblastic leukemia subtypes in Brazilian patients. Leuk Res 1996; 20;(4.);349-55. | Article | PubMed

33. Roberts GT, Aur RJ, Sheth KV: Immunophenotypic and age patterns of childhood acute lymphoblastic leukemia in Saudi Arabia. Leuk Res 1990; 14;(7.);667-72. | Article | PubMed

34. Taskov H, Dimitrova E, Serbinova M, Mendisova L, Bobev D: Immunological subtypes of childhood acute lymphoblastic leukemia in Bulgaria. Leuk Res 1995; 19;(11.);877-81. | Article | PubMed

35. Tiensiwakul P, Lertlum T, Nuchprayoon I, Seksarn P: Immunophenotyping of acute lymphoblastic leukemia in pediatric patients by three-color flow cytometric analysis. Asian Pac J Allergy Immunol 1999; 17;(1.);1721. | Article | PubMed

36. Chianese R, Brando B, Gratama JW: Diagnostic and prognostic value of flow cytometric immunophenotyping in malignant hematological diseases. J Biol Regul Homeost Agents 2002; 16;(4.);259-69. I PubMed

37. Larson RS, McCurley TL, 3rd: Relationship of CD4 and CD34 expression in acute leukemia. Blood 1995; 85;(12.);3768-9. | Article | PubMed

38. Bachir F, Bennani S, Lahjouji A, Cherkaoui S, Harif M, Khattab M, et al.: Characterization of acute lymphoblastic leukemia subtypes in moroccan children. Int J Pediatr 2009; 2009;(674801. | Article | PubMed Abstract | PubMed Full Text 